\title{
Density-dependent condition and growth of invasive lionfish in the northern Gulf of Mexico
}

\author{
Kristen A. Dahl ${ }^{1,2, *}$, Morgan A. Edwards ${ }^{2}$, William F. Patterson III ${ }^{2}$ \\ ${ }^{1}$ School of Natural Resources and Environment, University of Florida, Gainesville, FL 32611, USA \\ ${ }^{2}$ Fisheries and Aquatic Sciences, University of Florida, Gainesville, FL 32611, USA
}

\begin{abstract}
Absent natural population control, invasive red lionfish Pterois volitans (hereafter, lionfish) have reached record densities in the northern Gulf of Mexico (nGOM), though the role of density dependence on their population dynamics remains poorly understood. This study examined the effects of population density, sex, and habitat on lionfish condition (i.e. mass relative to total length) and size-at-age. Lionfish density was estimated with a remotely operated vehicle during 2010-2017 at a series of nGOM natural $(n=16)$ and artificial $(n=22)$ reefs, and individual lionfish $(n=3296)$ were sampled at additional reefs in the same system between 2013 and 2017. Mean lionfish total length increased across time, while density increased through 2015 and then stabilized or slightly declined. Lionfish density at artificial reefs was 2 orders of magnitude greater than at natural reefs throughout the study. Fish condition was lower on artificial reefs across all years, and lower on natural reefs during 2015-2017 versus 2013-2014. Age estimates obtained from sagittal otoliths ranged from 0.2-7.7 yr, corresponding to birth years between 2008 and 2016 . There were significant differences in growth and size-at-age between sexes and habitats, with males attaining larger sizes-at-age than females and fish growing faster at natural reefs. Significant declines in mean size-at-age and condition as a function of lionfish density were also observed. Overall, these results indicate condition and size-at-age displayed density-dependent effects that were likely due to inter- and intra-specific competition, which has important implications for invasive lionfish carrying capacity in the nGOM.
\end{abstract}

KEY WORDS: Otolith · Size-at-age $\cdot$ Invasive species $\cdot$ Population dynamics

\section{INTRODUCTION}

Indo-Pacific red lionfish Pterois volitans (Linnaeus, 1758) have extensively invaded the tropical and subtropical western Atlantic Ocean, including waters of the Caribbean Sea and Gulf of Mexico, over the last $30 \mathrm{yr}$ (Schofield 2010, Schofield et al. 2014). Part of their success in the invaded range is an ecological release from natural population control mechanisms otherwise present in their native range, such as predation, disease, and parasitism (Albins \& Hixon 2013, Tuttle et al. 2017). For example, predators do not appear to limit lionfish populations in the western Atlantic, thus resulting in greater densities and larger

*Corresponding author: kristenadahl@gmail.com body sizes than those reported for lionfish in the Pacific (Darling et al. 2011, Hackerott et al. 2013). Broad environmental tolerances have led to lionfish recruiting to a diversity of habitat types, including mangroves (Barbour et al. 2010), seagrass beds (Claydon et al. 2012), low relief hard-bottom reefs (Muñoz et al. 2011), mesophotic reefs (Lesser \& Slattery 2011), and artificial reefs (Dahl \& Patterson 2014). As generalist predators, lionfish are able to adapt to a variety of locally abundant prey (Côté \& Maljkovi 2010, Dahl et al. 2017). These attributes have contributed to lionfish being arguably the most successful marine fish invader recorded (Morris \& Akins 2009, Côté et al. 2013), which poses long-term

() The authors 2019. Open Access under Creative Commons by Attribution Licence. Use, distribution and reproduction are unrestricted. Authors and original publication must be credited. 
threats to native communities by directly altering community and trophic structure (Lesser \& Slattery 2011, Dahl et al. 2016), as well as by reducing prey fish biomass and species richness (Green et al. 2012, Dahl et al. 2016).

Lionfish occurrence in the northern Gulf of Mexico (nGOM) is relatively recent, where first sightings were reported off the southwest Florida coast in early 2010 (Schofield 2010). Lionfish were reported throughout the entire GOM basin less than 1 yr later (Fogg et al. 2013, Dahl \& Patterson 2014, Nuttall 2014). In the nGOM, lionfish densities increased exponentially in the following years on both natural and artificial reefs, with their densities on nGOM artificial reefs being among the highest in the western Atlantic (Dahl \& Patterson 2014). Lionfish in this region consume a broad diversity of fish and invertebrate prey, and exhibit habitat-specific and ontogenetic trends in feeding ecology (Dahl \& Patterson 2014, Dahl et al. 2017). Most recently, extensive density-dependent cannibalism also has been documented in the region (Dahl et al. 2018).

Given the high abundance and wide distribution of lionfish in the invaded range, eradication of the species is thought to be unachievable (Côté et al. 2013). Targeted lionfish removals are currently the best management option available to reduce lionfish biomass and body size in regions where lionfish are already having negative impacts (Barbour et al. 2011, Frazer et al. 2012, Dahl et al. 2016). Population and ecosystem models may be used to estimate the removal effort necessary to reduce lionfish biomass and mitigate negative impacts (Morris et al. 2011, Chagaris et al. 2017), but these approaches rely heavily on age and growth estimates to parameterize and model population dynamics across time (Kolar \& Lodge 2001, Morris et al. 2011).

Lionfish age and growth parameters have been estimated from several locations within the western Atlantic; however, data sets often exhibit a truncated age structure because sampling has occurred within too few years following colonization (Potts et al. 2010, Edwards et al. 2014, Johnson \& Swenarton 2016, Fogg 2017). Furthermore, lionfish population dynamics are likely to change as the invasion progresses (Bøhn et al. 2004, Gutowsky \& Fox 2012). This is because the population growth of most invasive species follows a predictable trajectory which starts with a lag period of low densities, increases to exponential growth and high densities, and eventually peaks near carrying capacity (Crooks \& Soule 1999, Sakai et al. 2001). Thus, through the process of invasion and establishment a species may experience both density- independent and density-dependent factors based on the demographic and environmental conditions present, resulting in phenotypic changes in life history traits, such as growth or fecundity (Bøhn et al. 2004). As the invasive lionfish population reaches carrying capacity in the nGOM, density-dependent processes, including decreased growth, may begin to regulate lionfish populations in the region via increased inter- and intra-specific competition for prey resources.

Here, we report age and growth estimates for lionfish sampled during 2013-2017 at natural and artificial reefs in an approximately $25000 \mathrm{~km}^{2}$ region of the nGOM. Specific objectives were to (1) track regional habitat-specific lionfish densities and update through 2017 the 2010-2013 time series reported by Dahl \& Patterson (2014), (2) estimate lionfish growth and condition patterns, and (3) test for the presence of density-dependent effects on lionfish condition (massat-length relative to the population) and size-at-age. The data presented herein are unique given their comprehensive nature and the time series over which sampling occurred, thus enabling the examination of density-dependent feedbacks as the nGOM invasive lionfish population reached its apparent peak.

\section{MATERIALS AND METHODS}

\subsection{Study location and specimen collection}

All applicable institutional and/or national guidelines for the care and use of animals were followed during the course of this study. Lionfish density estimation occurred at offshore $(>10 \mathrm{~km})$ nGOM artificial and natural reefs across the Florida shelf between 2013 and 2017. Remotely operated vehicle (ROV) sampling was conducted within this region following the methods and at the same reef locations reported by Dahl \& Patterson (2014) for all years. The purpose of ROV sampling was to track regional habitat-specific lionfish densities and update through 2017 the 2010-2013 time series reported by Dahl \& Patterson (2014). ROV sampling was conducted at artificial reefs with a point-count method described by Patterson et al. (2009), where the ROV was used to sample a $15 \mathrm{~m}$ cylinder with reefs at the center of the cylinder's base. At natural reefs, ROV sampling was conducted with a transect method, where four $25 \mathrm{~m}$ transects were made at a fixed height off the seafloor (Dahl \& Patterson 2014).

Lionfish were sampled for age and growth analyses via spearfishing at other artificial and 
natural reefs in the same system (Fig. 1), with sampling reefs ranging in depth from 24-54 m. Artificial reef study sites were primarily concrete modules consisting of single pyramid, paired tetrahedron, or paired reef balls deployed in 2003 by the Florida Fish and Wildlife Conservation Commission (FWC) within the Escambia-East and Okaloosa-C Large Area Artificial Reef Sites (LAARS) south of Pensacola and Destin, FL, USA, respectively (Dance et al. 2011). Other artificial habitats sampled included larger concrete pyramids, decommissioned oil platforms, and small shipwrecks. Natural reef habitat sampled by divers off northwest Florida included carbonate or sandstone outcrops with vertical relief $\leq 3 \mathrm{~m}$, and moderately sloping ridges of rock rubble and shell hash with little vertical relief (Thompson et al. 1999). Lionfish spearing was localized immediately posterior to the head which severed their spinal column. At the surface, fish were placed in mesh bags in an ice-slurry. Each lionfish was weighed to the nearest $0.1 \mathrm{~g}$, measured to the nearest $\mathrm{mm}$ total length (TL), and sex was determined by macroscopic examination of gonads. Both sagittal otoliths were extracted, cleaned, and stored dry in $0.5 \mathrm{ml}$ microcentrifuge tubes for age determination.

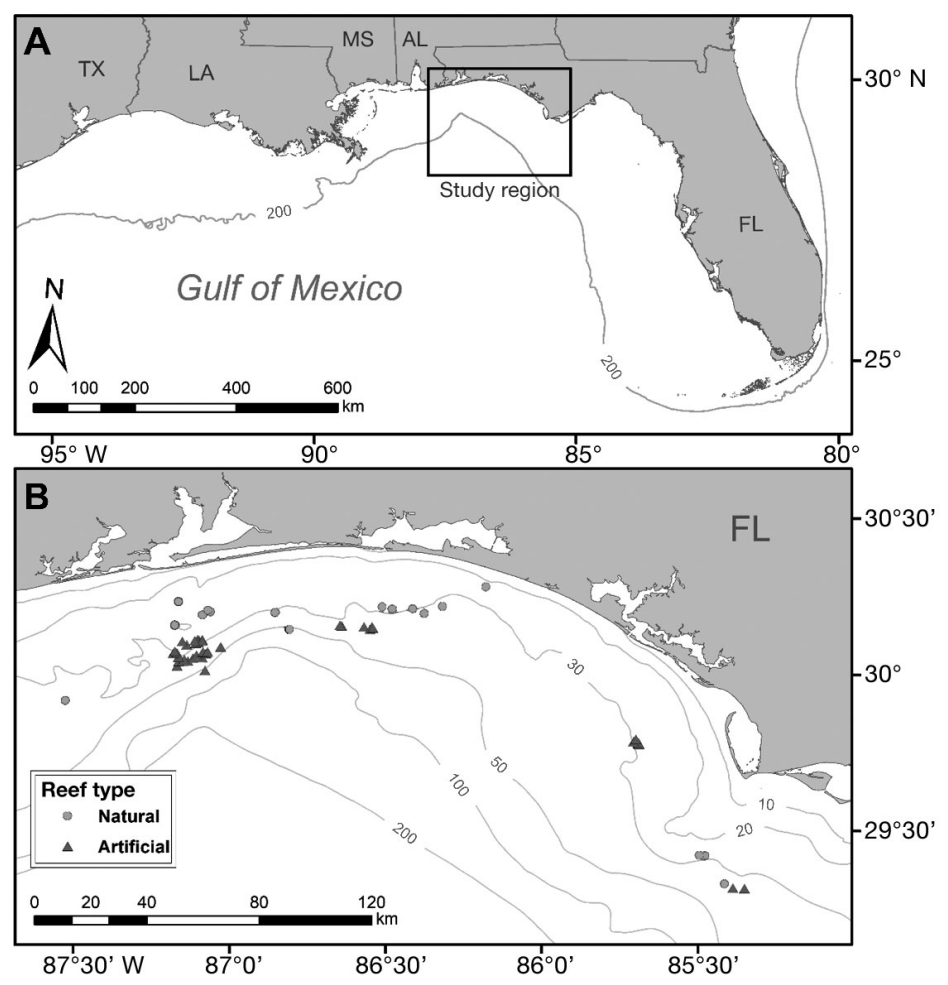

Fig. 1. Northern Gulf of Mexico indicating (A) study region and (B) natural and artificial reefs where lionfish were sampled. Isobaths are indicated from 10 to $200 \mathrm{~m}$

\subsection{Weight-length relationships and condition}

A weight-length non-linear regression was computed for all lionfish collected in the study following the power relationship:

$$
W=a L^{b}
$$

where $W$ is wet mass $(\mathrm{kg}), L$ is TL $(\mathrm{mm}), a$ is the allometric relationship coefficient between mass and length, and $b$ is the exponent of that relationship.

Relative condition factor $\left(K_{n i}\right.$ Le Cren 1951) was computed to examine condition relative to fish in the population from which the individual was sampled:

$$
K_{n}=\frac{W}{a L^{b}}
$$

where $W$ and $L$ are variables as defined above, and $a$ and $b$ parameters were derived from the non-linear regression of lionfish weight and length. A 3-factor ANOVA was computed to test the effects of sex, habitat, time (i.e. early [2013-2014] versus late [2015-2017]), and their interactions on $K_{n}$. In this analysis, timing served as a proxy for lionfish density given that lionfish density increased across study years but could not be estimated for all reefs where lionfish were sampled.

\subsection{Age estimation}

Left sagittal otoliths were embedded in epoxy and then sectioned in a transverse plane with a diamond-bladed low-speed saw to approximately $0.4 \mathrm{~mm}$ thickness. Opaque zones were counted along the sulcus under a dissecting microscope with transmitted light and a polarizing light filter at a 20-64× magnification and without knowledge of date or location of capture, morphometric data, or opaque zone counts of a second reader (see below). Otolith margins were scored as being either opaque or translucent, and width was recorded following Beckman et al. (1991). Timing of opaque zone formation was evaluated by plotting marginal condition by month for all data pooled among years.

Otolith readability scores were assigned from 1 (unreadable) to 4 (excellent) to determine otoliths suitable for final analysis. A randomly selected subset $(\mathrm{n}=1000)$ of sectioned otoliths was read by a second (M.A.E.) independent reader without knowledge of fish size or the 
first (K.A.D.) reader's age estimate. Average percent error (APE) was calculated to assess precision of age estimates between readers (Beamish \& Fournier 1981):

$$
A P E=\frac{\sum_{j=1}^{n} A P E_{j}}{n} \text { where } A P E_{j}=100 \times \frac{\sum_{i=1}^{R} \frac{\left|x_{i j}-\bar{x}_{j}\right|}{\bar{x}_{j}}}{R}
$$

where $A P E_{j}$ is the average percent error for the $j^{\text {th }}$ fish, $x_{i j}$ is the $i^{\text {th }}$ age estimate on the $j^{\text {th }}$ fish, $\bar{x}_{j}$ is the mean age estimate for the $j^{\text {th }}$ fish, $R$ is the number of times each fish was aged, and $n$ is the number of aged fish in the sample. Precision is known to be influenced by the species under study; thus, there are no critical levels for what constitutes an acceptable $a$ priori APE (Campana 2001). Furthermore, because APE is sensitive to truncated age composition (Hoenig et al. 1995, Soupir et al. 1997) and age disagreements for young fish (Kimura \& Lyons 1991), APE values between 5 and $10 \%$ are commonly reported, especially for fish that are difficult to age (reviewed in Campana 2001). Primary reader counts were utilized to estimate age and growth.

Integer age estimates were used in all analyses with the exception of von Bertalanffy growth models. Lionfish integer age (in years) was assigned from the number of opaque zones present in otolith sections under the previously verified assumption that opaque zones form annually (Edwards et al. 2014, Fogg 2017). For samples collected close to the timing of opaque zone formation (i.e. March-April), integer age was sometimes adjusted \pm 1 yr based on margin condition (i.e. following the methods of Beckman et al. 1991). A year was added for fish collected between March and May with a translucent margin $>2 / 3$ the thickness of the previous translucent margin (i.e. late forming opaque zone). A year was subtracted for fish collected in December through February with an opaque margin $<1 / 3$ the thickness of the previous opaque margin (i.e. early forming opaque zone).

Fractional age was estimated from the number of opaque zones, assumed birthdate, timing of opaque zone formation, and capture date. A mean birthdate of 1 July was based on peak lionfish spawning in the nGOM (Fogg et al. 2017). We assumed opaque zone formation was annual and began on 1 March based on previous studies (Edwards et al. 2014, Fogg 2017), as well as data reported below. Fractional age was estimated by first subtracting one opaque zone from the total count for a given otolith and then multiplying the difference by $365 \mathrm{~d}$. Next, $274 \mathrm{~d}$ were added to account for the first calendar year of life (1 July to 1 March). Finally, the day of the year that a fish was sampled (days since 1 March) was added to account for the number of days in the sampling year that the fish was alive since it began forming its last opaque zone (or since birth in the case of otoliths with zero opaque zones). This result was divided by $365 \mathrm{~d}$ to estimate fractional age in years. Similar to integer age estimation methods above, adjustments were made based on margin condition to assign correct age class for some fish. For fish sampled in December-February that had early opaque zone formation, 2 was subtracted from the total number of opaque zones before multiplying by $365 \mathrm{~d}$. For fish sampled in March-May that had not yet begun forming an opaque zone, zero was subtracted from the total number of opaque zones before multiplying by $365 \mathrm{~d}$.

Lionfish growth was estimated by fitting the von Bertalanffy growth function (VBGF; von Bertalanffy 1938) to observed TL-at-age data using fractional age estimates:

$$
L_{t}=L_{\infty}\left(1-\mathrm{e}^{-k\left[t-t_{0}\right]}\right)
$$

where $L_{t}=$ predicted TL $(\mathrm{mm})$ at age $t_{i} L_{\infty}=$ asymptotic TL; $k=$ Brody's growth coefficient; $t=$ age $(\mathrm{yr})$; and $t_{0}=$ hypothetical age at zero length.

Separate models were fit for all lionfish pooled, as well as for each sex by habitat type, using the nonlinear least squares function in R v.3.4 (R Core Team 2016) to estimate the $L_{\infty}, k$, and $t_{0}$ parameters of each model. Sex-specific models were calculated with all juveniles (i.e. fish of undetermined sex <180 mm TL) included in each model.

A 3-factor ANOVA was computed to test the effect of sex and habitat on mean size-at-age of the more common ages (1-6 yr). Main effects in the model were habitat, sex, and integer age; significant interactions with integer age were compared by age to test for significant habitat, sex, or habitat $\times$ sex effects.

To assess the effect of density on size-at-age, lionfish density (fish $100 \mathrm{~m}^{-2}$ ) was estimated on select LAARS artificial reefs $(n=16)$ where fish were sampled with spears from the number of lionfish removed and known sampling area $\left(176 \mathrm{~m}^{2}\right)$. Removal effort (i.e. number of divers, search area) was consistent among artificial reefs sampled, and we assumed independence of size-at-age estimates from each site given reefs were sampled once. The effect of lionfish density on size-at-age was tested with analysis of covariance (ANCOVA) using the ' $\mathrm{lm}$ ' function in $\mathrm{R}$ v.3.4 (R Core Team 2016), where sex (i.e. male, female) and age class (i.e. age-2, age-3, age-4) were treated as covariates. ANCOVA was utilized to test 
for differences in size-at-age as a function of density while accounting for differences in initial sizes among these groups. We tested for significant interaction terms between the factor and covariates, and removed non-significant interactions from the final model. The effect of lionfish density on $K_{n}$ was tested with linear regressions of mean $K_{n}$ versus lionfish density, where mean $K_{n}$ represents all individuals at a given artificial reef.

\section{RESULTS}

\subsection{Density trends}

Densities estimated by ROV sampling on individual study reefs ranged from $0.0-1.9$ fish $100 \mathrm{~m}^{-2}$ on natural reefs and from $0.0-90.4$ fish $100 \mathrm{~m}^{-2}$ on artificial reefs. An exponential increase in lionfish density at both natural and artificial reefs was observed beginning in 2011 through 2014, after which mean lionfish density on both reef types reached an apparent peak (Fig. 2). By 2013, mean densities on artificial reefs (14.7 fish $100 \mathrm{~m}^{-2}$ ) were 2 orders of magnitude higher than on natural reefs (0.49 fish $\left.100 \mathrm{~m}^{-2}\right)$, a trend which continued through 2017 (Fig. 2). The highest mean density on artificial reefs (32.98 fish $100 \mathrm{~m}^{-2}$ ) was observed in 2014, after which densities

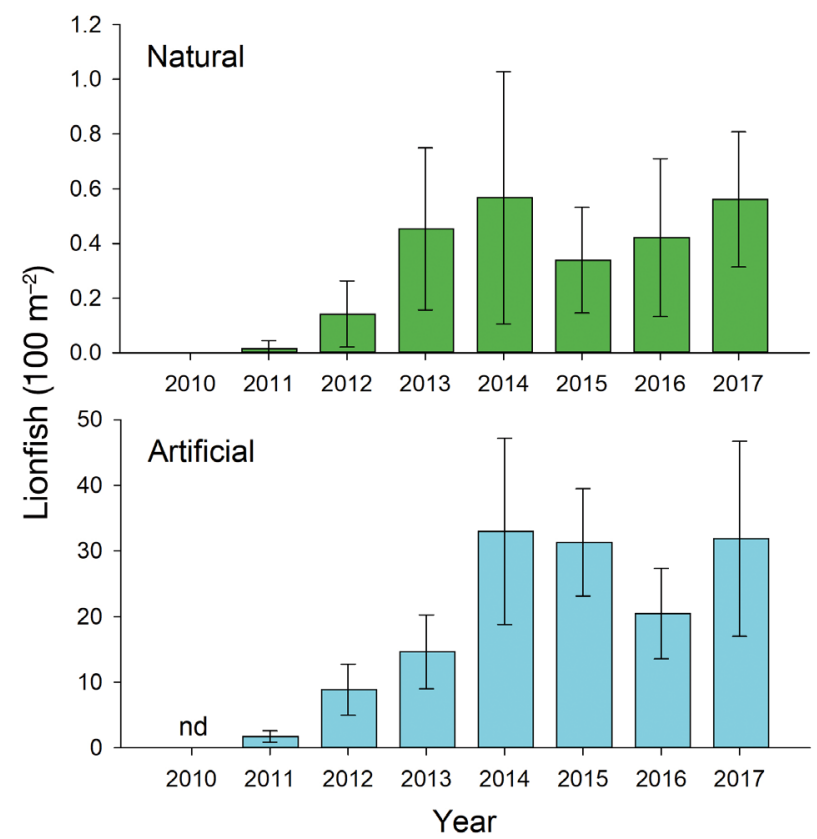

Fig. 2. Invasive lionfish mean density $( \pm 95 \% \mathrm{CI}$ ) estimated from remotely operated vehicle video samples at northern Gulf of Mexico natural $(n=16)$ and artificial $(n=22)$ reef locations reported by Dahl \& Patterson (2014), updated through 2017 declined through 2016 to 20.45 fish $100 \mathrm{~m}^{-2}$. By 2017, mean density recovered to peak values observed on artificial reefs in 2014. Densities on natural reefs displayed similar temporal trends with the highest mean density ( 0.57 fish $100 \mathrm{~m}^{-2}$ ) observed in 2014, followed by a decline in $2015\left(0.34\right.$ fish $\left.100 \mathrm{~m}^{-2}\right)$, and stabilizing (i.e. increasing) through 2017 (Fig. 2).

\subsection{Population demographics}

Between 2013 and 2017, divers collected a total of 3296 lionfish samples for this study, with 2066 fish from artificial habitats and 1230 from natural habitats (Table S1). Sample sizes were relatively similar between habitats among years; however, no fish were collected from natural reef habitats in 2015, or from artificial habitats in 2017 (Table S1 in the Supplement at www.int-res.com/articles/suppl/m623p145_supp. pdf). Lionfish samples consisted of 1338 males and 1609 females (1:1.2 ratio). Sex was not determined for 349 fish, $73.3 \%$ of which were smaller than mean size at maturity ( $<180 \mathrm{~mm}$ TL; Morris et al. 2009).

Lionfish ranged from $67-410 \mathrm{~mm}$ TL and 0.004$0.99 \mathrm{~kg}$ in mass (Fig. 3). Male lionfish were on average larger in size compared to females (Fig. 4). Age1 males were $180 \mathrm{~mm}$ TL on average but were as large as $265 \mathrm{~mm} \mathrm{TL}$; age-1 females were on average $168 \mathrm{~mm}$ TL but as large as $256 \mathrm{~mm}$ TL. Mean $( \pm \mathrm{SE})$ TL was $272.71 \pm 1.52 \mathrm{~mm}$ for males, $238.51 \pm 1.17 \mathrm{~mm}$ for females and $135.39 \pm 1.49 \mathrm{~mm}$ for juveniles.

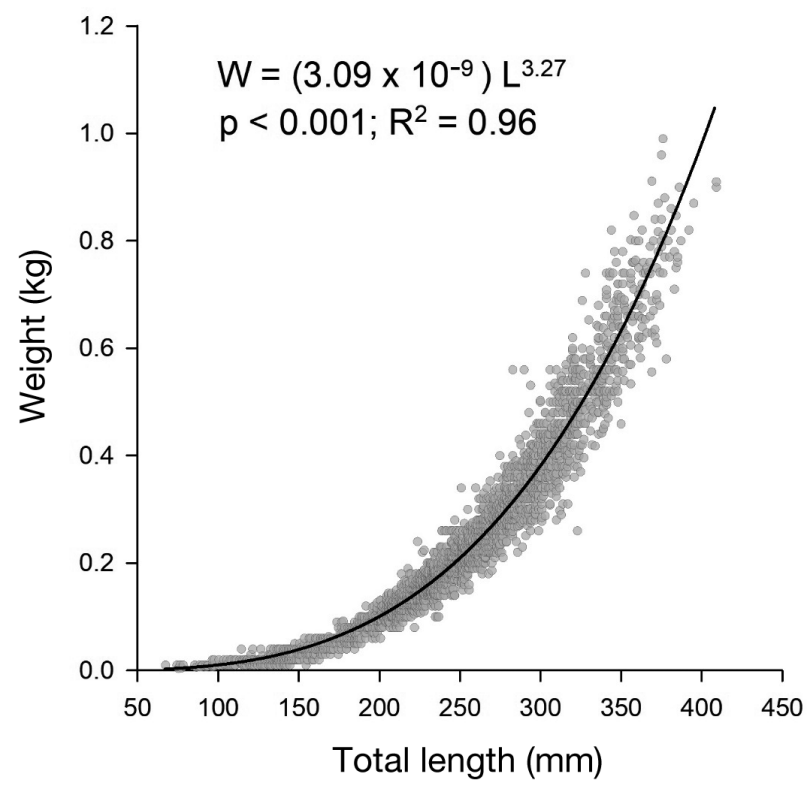

Fig. 3. Length-weight relationship for lionfish $(\mathrm{n}=3266)$ sampled in the northern Gulf of Mexico between 2013 and 2017 


\subsection{Weight-length relationships and body condition}

Length frequency distributions revealed steady increases in lionfish body size over time, coupled with a noticeable lack of smaller, younger cohorts in 2016 and 2017 (Fig. 4). For females, mass (kg) related to TL $\left(\mathrm{p}<0.001 ; \mathrm{R}^{2}=0.95\right)$ according to: $W=3.36 \times 10^{-9} L^{3.25}$, and for males, this relationship $\left(\mathrm{p}<0.001 ; \mathrm{R}^{2}=0.96\right)$ was: $W=2.75 \times 10^{-9} L^{3.28}$, Log-transformed weightlength relationships were not significantly different between males and females (ANCOVA test for equal slopes; $F_{1,3976}=3.02, \mathrm{p}=0.083$ ), thus parameters fit to pooled data were used to calculate $K_{n}$ of lionfish. For pooled data from juveniles, males, and females, mass related to TL ( $p<0.001 ; \mathrm{R}^{2}=0.96$; Fig. 3 ) according to: $W=3.09 \times 10^{-9} L^{3.27}$.

Visual analysis of $K_{n}$ data and residual plots revealed that the assumptions of normality and homoscedasticity were met and were appropriate given a large sample size $(\mathrm{n}=2909)$. $K_{n}$ was significantly different by habitat (ANOVA, $F_{1,2908}=272.85, \mathrm{p}<$ 0.001 ), time (ANOVA, $F_{1,2908}=4.59, \mathrm{p}=0.032$ ), and their interaction (ANOVA, $F_{1,2908}=11.65$, p $<0.001$ ) (Table 1, Fig. 5). $K_{n}$ was higher on natural reefs compared to artificial reefs for both early $(p<0.001)$ and late invasion ( $\mathrm{p}<0.001$ ) time periods (Fig. 5, Table S2). $K_{n}$ was higher in the early invasion time period compared to later years on natural reefs ( $p<0.001)$, but was not significantly different between time periods on artificial reefs $(\mathrm{p}=0.290)$ (Fig. 5, Table S2). There was no significant effect of sex on $K_{n}$ of lionfish in this study (Table 1, Fig. 5).

\subsection{Age estimates, precision, and margin condition}

Of the 3145 sagittal otoliths undamaged and prepared for age estimation, age could be determined for 3081 individual fish. Otoliths with readability scores $>1$ were aged, with $22.4 \%$ of otolith sections scored as 2 (difficult), $61.3 \%$ scored as 3 (readable), and 16.3\% scored as 4 (excellent). The overall APE between independent readers was $8.5 \%$ among 1000 otoliths. Agreement between readers was high (60.1\%), and $93 \%$ of disagreements were within one opaque zone. Disagreements in counts did not exceed 2 zones, and there was no evidence of systematic aging bias (i.e. directionality; Fig. S1). The frequency of disagreements increased with lower readability scores, but readability scores for twice-read sections were not proportionally different from those of the full sample.
Marginal condition analysis demonstrated a trend in opaque zone completion occurring during winter/ spring (Fig. 6). Otolith opaque zones generally began forming in February, with a peak in complete otolith opaque margins (>80\%) in March and April. Translucent margins were dominant (>50\%) in samples collected between August and January, with the highest proportion of translucent margins occurring in January.

\subsection{Population dynamics and growth}

Otolith opaque zones revealed integer ages from age- 0 to age- $7 \mathrm{yr}$, with each age class comprising, on average, $1.3,11.1,29.7,29.8,17.3,8.1,2.3$, and $0.3 \%$ of samples, respectively (Fig. 4). Among all years, lionfish had a mean $( \pm \mathrm{SE})$ age of $2.87 \pm 0.02 \mathrm{yr}$, and $88 \%$ of individuals were between the ages of 1 and 4 yr (Fig. 4). Fractional ages were estimated to be as young as $0.2 \mathrm{yr}$ old. The oldest estimated fractional ages came from a $408 \mathrm{~mm}$ male estimated to be $7.3 \mathrm{yr}$ old, and a $304 \mathrm{~mm}$ female estimated to be $7.7 \mathrm{yr}$ old. Estimated ages corresponded to birth years and settlement between 2008 and 2016.

The 4 VBGFs computed separately for females and males by habitat type exhibited differential growth and resulted in different parameter values (Table 2, Fig. 7). All lionfish exhibited rapid growth in the first 1-3 yr of life, after which growth slowed towards $L_{\infty}$ (Fig. 7). Females were predicted to grow faster towards $L_{\infty}$ than males on both artificial $(k=0.281$ versus $\left.0.253 \mathrm{yr}^{-1}\right)$ and natural $(k=0.385$ versus $0.245 \mathrm{yr}^{-1}$ ) reefs (Fig. 7). Males had larger $L_{\infty}$ on both artificial $\left(L_{\infty}=439.4 \mathrm{~mm}\right.$ TL for males versus $364.7 \mathrm{~mm}$ for females) and natural $\left(L_{\infty}=456.4 \mathrm{~mm} \mathrm{TL}\right.$ for males versus $325.5 \mathrm{~mm}$ for females) habitats, thus demonstrating sexually dimorphic growth (Fig. 7). The model fit to data from all lionfish resulted in intermediate parameter values of $L_{\infty}$ (381.3 $\left.\mathrm{mm} \mathrm{TL}\right)$ and $k\left(0.302 \mathrm{yr}^{-1}\right.$; Table 2$)$. Estimates of $t_{0}$ ranged from -0.44 to -0.62 yr among growth models (Table 2, Fig. 7).

Differences in nGOM lionfish size were also demonstrated by the significant interaction between the effects of age, sex, and habitat on mean size-atage (ANOVA, p < 0.001) of lionfish aged 1-6 yr old (Table 3, Fig. 8). Males were larger compared to females across all age classes and in both habitats $(\mathrm{p}<$ 0.001; Table S3), with the exception of age-1 fish on natural reefs ( $p<0.356$; Table S3, Fig. 8). Differences in size-at-age by habitat depended on both sex and age class (Fig. 8). Females from natural reefs were 

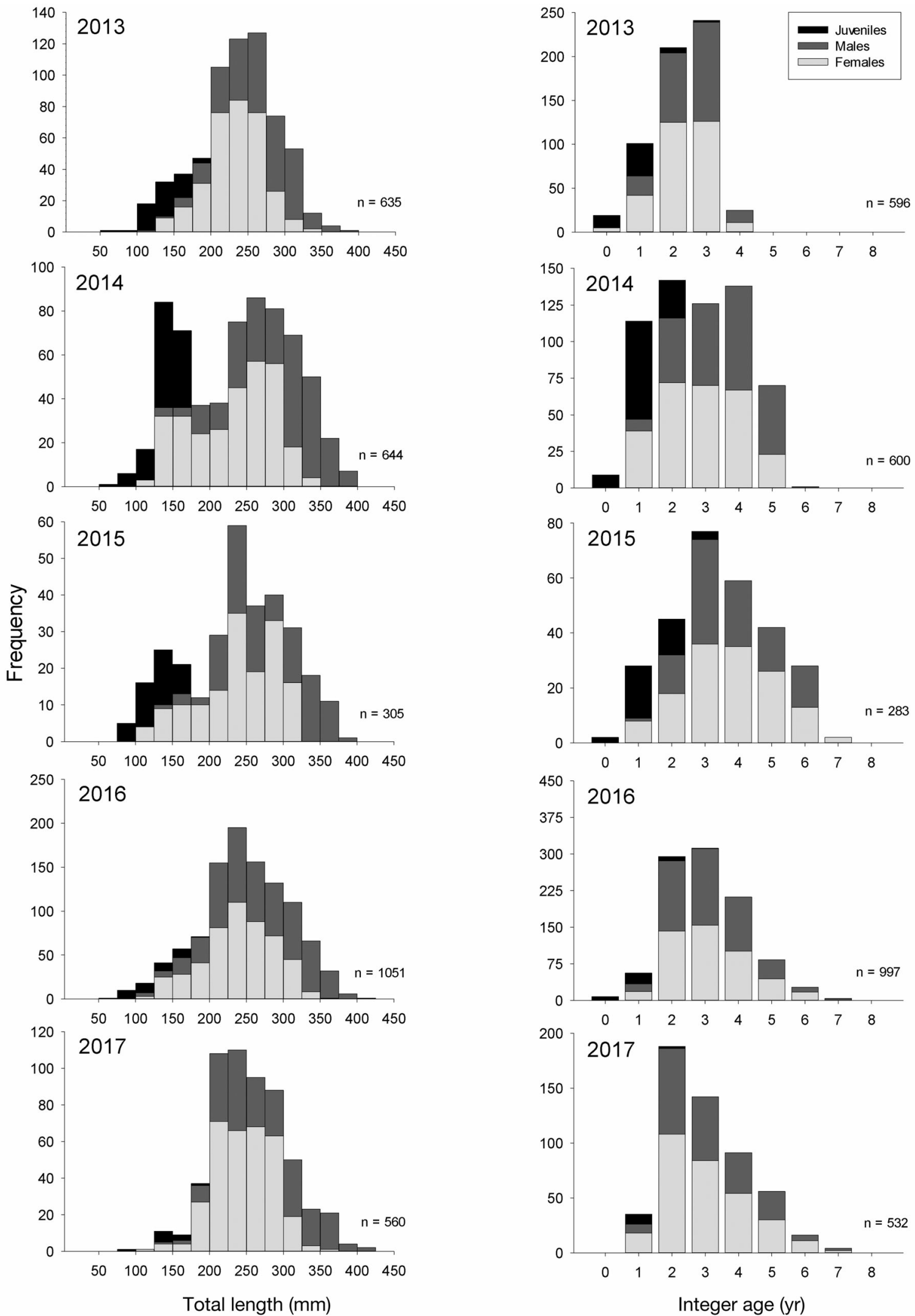

Fig. 4. Total length (left) and age distributions (right) of lionfish sampled in the northern Gulf of Mexico during 2013-2017 
Table 1. Results of 3-factor ANOVA for model computed to test the effect of sex, habitat, time (early versus late invasion), and interactions on relative condition factor, $K_{n}$, of northern Gulf of Mexico lionfish samples. Factor levels: time: early invasion (2013-2014), late invasion (2015-2017); sex: female, male; habitat: artificial reef, natural reef

\begin{tabular}{|lccccc|}
\hline Source & df & SS & MS & $F$ & $\mathrm{p}$ \\
\hline Time & 1 & 0.084 & 0.084 & 4.59 & 0.032 \\
Sex & 1 & 0.004 & 0.004 & 0.23 & 0.634 \\
Habitat & 1 & 4.963 & 4.963 & 272.85 & $<0.001$ \\
Time $\times$ sex & 1 & 0.001 & 0.001 & 0.01 & 0.926 \\
Time $\times$ habitat & 1 & 0.212 & 0.212 & 11.65 & $<0.001$ \\
Sex $\times$ habitat & 1 & 0.001 & 0.001 & 0.02 & 0.901 \\
Time $\times$ sex $\times$ habitat & 1 & 0.060 & 0.060 & 3.30 & 0.069 \\
Residual & 2901 & 52.763 & 0.018 & & \\
Total & 2908 & 57.898 & 0.020 & & \\
\hline
\end{tabular}

significantly larger than those from artificial reefs for age-1 ( $\mathrm{p}<0.001)$, age-2 ( $<<0.001)$, and age-3 fish $(p=0.002)$, but those differences were not statistically significant for age-4, age-5, or age-6 fish (Table S3, Fig. 8). A similar trend was seen in males, where fish from natural reefs were significantly larger than those from artificial reefs for age- $2(p=0.004)$, age- 3 $(\mathrm{p}<0.001)$, and age-4 fish $(\mathrm{p}<0.001)$, but not for age- 1 , age-5, or age- 6 fish (Table S3, Fig. 8). A lack of sufficient sample sizes precluded the ability to include 0 and 7-yr age classes in size-at-age analyses.

Lionfish density estimated by the number of lionfish removed on study artificial reefs ranged from 6.8-78.4 fish $100 \mathrm{~m}^{-2}$. An ANCOVA of mean size-atage for ages $2-4 \mathrm{yr}$ versus lionfish density revealed density had a significant effect on lionfish size-at-age $\left(F_{4,64}=172.1, \mathrm{p}<0.001, \mathrm{R}^{2}=0.91\right)$, where size decreased linearly with increasing lionfish density

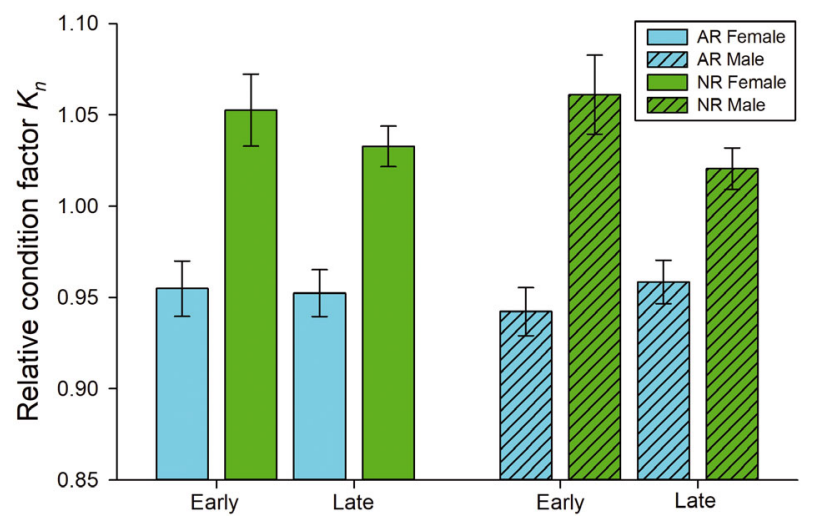

Fig. 5. Mean $( \pm 95 \% \mathrm{CI}$ ) relative condition factor of northern Gulf of Mexico lionfish by habitat, sex, and invasion timing. AR: artificial reef; NR: natural reef; early: 2013-2014; late: 2015-2017

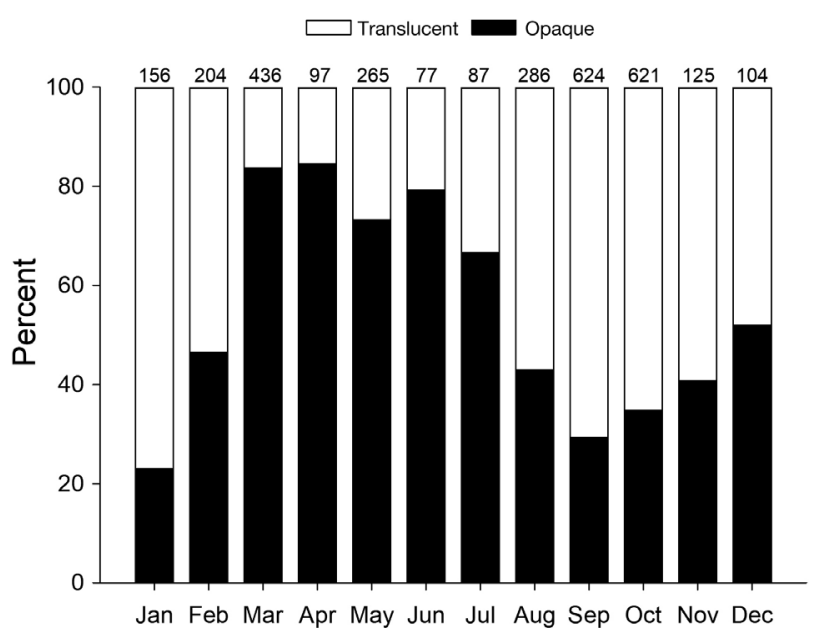

Fig. 6. Trend in lionfish otolith marginal condition $(\mathrm{n}=3082)$ among months for fish sampled in the northern Gulf of Mexico between 2013 and 2017. Numbers above bars: aggregate monthly sample sizes

(Fig. 9). Covariates age class $(\mathrm{p}<0.001)$ and sex $(\mathrm{p}<$ 0.001 ) were also significant in the final model (size-atage $\sim$ density + age class + sex), where they affected the intercepts of linear models (Fig. 9). No significant interactions were observed between density and the covariates age class and sex; thus, the assumption of equal slopes was met, and the slope of the linear relationship between size-at-age and density was not significantly different among all combinations of age class and sex (Fig. 9). The linear regression of mean $K_{n}$ versus lionfish density was significant $\left(F_{1,13}=5.21\right.$, $\mathrm{p}=0.041, \mathrm{R}^{2}=0.30$ ), and $K_{n}$ decreased linearly with increasing lionfish density (Fig. 10).

\section{DISCUSSION}

\subsection{Density-dependent growth and condition}

Age and growth estimates reported here yield key insights into the life history and population dynamics of invasive lionfish from both artificial and natural reef habitats across the Florida shelf of the nGOM over a $5 \mathrm{yr}$ period of invasion, which in turn has important implications for regional carrying capacity. Clear evidence exists to indicate density-dependent effects on growth and condition of invasive lionfish in the nGOM. Lionfish inhabiting densely populated artificial reefs exhibited smaller mean size-at-age, hence slower growth, and lower body condition compared to natural reefs, suggesting habitat effects were likely due to differences in lionfish density. On natural reefs, lionfish displayed lower body condition in 
Table 2. Parameters of von Bertalanffy growth models estimated for all lionfish, and lionfish grouped by sex and habitat combinations sampled from the northern Gulf of Mexico. Von Bertalanffy growth model parameters $( \pm 95 \% \mathrm{CI})$ are $L_{\infty}$ : asymptotic maximum length; $k$ : Brody's growth coefficient; $t_{0}$ : theoretical age when total length equals 0 . AR: artificial reef; NR: natural reef

\begin{tabular}{|lccccc|}
\hline Model group & $\mathrm{n}$ & $\begin{array}{c}L_{\infty} \\
(\mathrm{mm})\end{array}$ & $\begin{array}{c}k \\
\left(\mathrm{yr}^{-1}\right)\end{array}$ & $\begin{array}{c}t_{0} \\
(\mathrm{yr})\end{array}$ & $\mathrm{R}^{2}$ \\
\hline All lionfish & 2996 & $381.3 \pm 14.4$ & $0.302 \pm 0.031$ & $-0.519 \pm 0.127$ & 0.69 \\
Female AR & 1090 & $364.7 \pm 23.9$ & $0.281 \pm 0.047$ & $-0.616 \pm 0.188$ & 0.75 \\
Female NR & 653 & $325.5 \pm 15.0$ & $0.385 \pm 0.063$ & $-0.562 \pm 0.219$ & 0.73 \\
Male AR & 967 & $439.4 \pm 36.5$ & $0.253 \pm 0.049$ & $-0.439 \pm 0.190$ & 0.75 \\
Male NR & 527 & $456.4 \pm 48.6$ & $0.245 \pm 0.061$ & $-0.572 \pm 0.263$ & 0.77 \\
\hline
\end{tabular}

later years (2015-2017) of the invasion as lionfish biomass continued to increase steadily. Declines in mean size-at-age and condition with increasing lionfish density on artificial reefs provide additional evi- dence of a density-dependent feedback on growth in invasive lionfish in the region. While reported experimentally in juvenile ( $\leq 71 \mathrm{~mm}$ TL) lionfish (Benkwitt 2013), this is the first evidence of density-dependent effects on growth occurring in adults of this invasive species.

Released from typical constraints on population growth, such as predation, competition, and habitat availability, lionfish populations have reached high density and biomass in their introduced range (Darling et al. 2011, Kulbicki et al. 2012), but all invasive species must eventually reach carrying capacity (Lockwood et al. 2007). Mean lionfish density on studied artificial reefs in the nGOM were nearly 10 fish $100 \mathrm{~m}^{-2}$ within $2 \mathrm{yr}$ of colonizing the region and were as high as 33 fish $100 \mathrm{~m}^{-2}$ by 2014 (Dahl \& Patterson 2014, Dahl et al. 2016). Alternatively, mean density on natural reefs remained $<1$ fish $100 \mathrm{~m}^{-2}$ throughout this study, 2 orders of magnitude lower

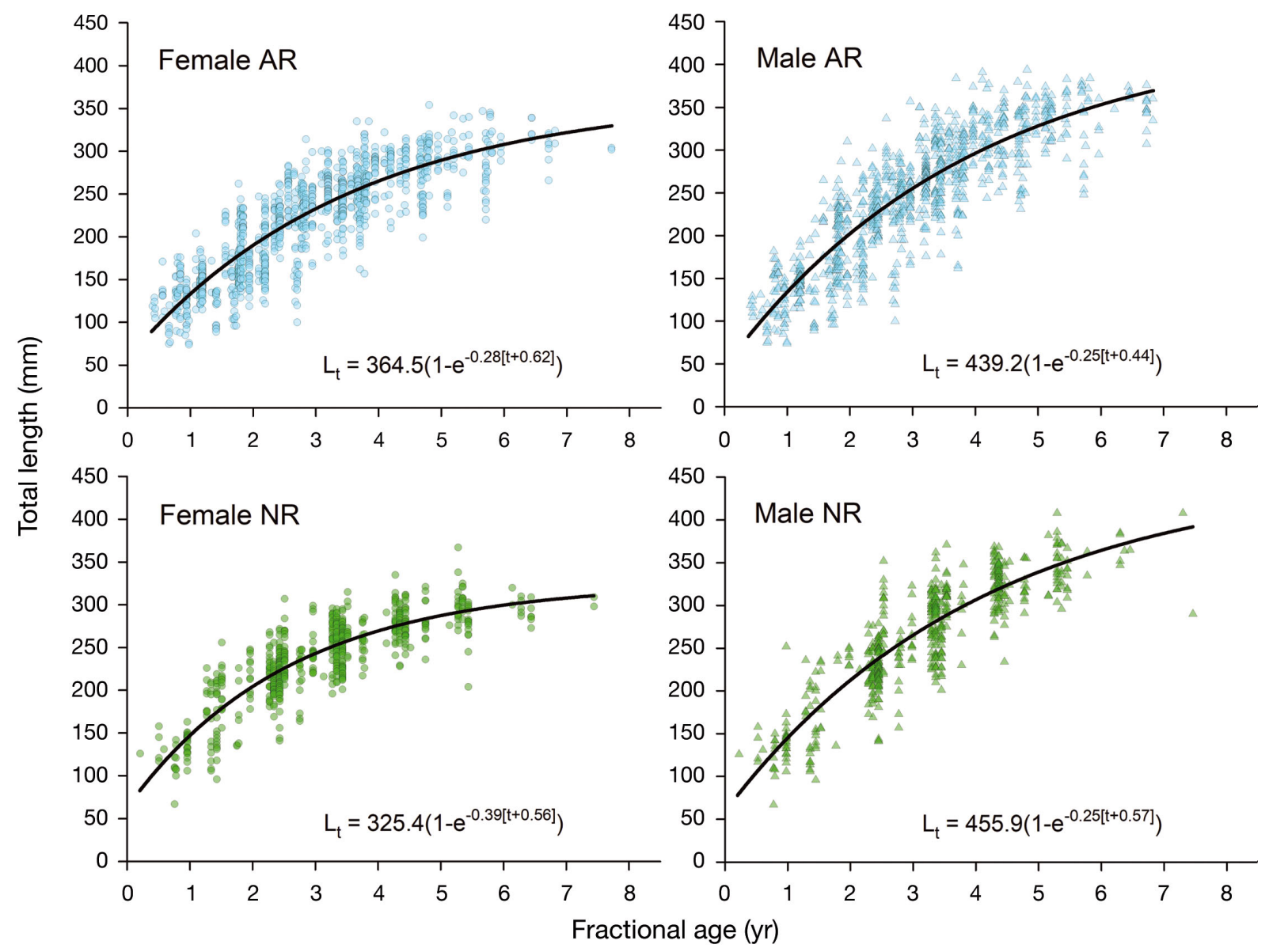

Fig. 7. Sex- and habitat-specific scatterplots of lionfish total length versus age. Data for juveniles (fish $<180 \mathrm{~mm}$ total length with unassigned sex) were allocated to both sexes. Plotted lines: von Bertalanffy growth function fits to the data, with functions given on each panel. Circles: females; triangles: males. AR: artificial reef; NR: natural reef 
Table 3. Results of 3-factor ANOVA for model computed to test the effects of sex, habitat, and integer age on total length $(\mathrm{mm})$ of northern Gulf of Mexico lionfish. Factor levels: sex: female, male; habitat: artificial reef, natural reef; age: $1-5$ yr

\begin{tabular}{|c|c|c|c|c|c|}
\hline Source & df & SS & MS & $F$ & $\mathrm{p}$ \\
\hline Age & 5 & 3866909 & 773382 & 852.30 & $<0.001$ \\
\hline Habitat & 1 & 23718 & 23718 & 26.14 & $<0.001$ \\
\hline Sex & 1 & 301271 & 301271 & 332.02 & $<0.001$ \\
\hline Age $\times$ habitat & 5 & 4741 & 948 & 1.05 & 0.389 \\
\hline Age $\times \operatorname{sex}$ & 5 & 80561 & 16112 & 17.76 & $<0.001$ \\
\hline Habitat $\times$ sex & 1 & 587 & 587 & 0.65 & 0.421 \\
\hline Age $\times$ habitat $\times$ sex & 5 & 24645 & 4929 & 5.43 & $<0.001$ \\
\hline Residual & 2715 & 2463596 & 907 & & \\
\hline Total & 2738 & 7697847 & 2811 & & \\
\hline
\end{tabular}

than those recorded on artificial reefs. Lionfish density trends across habitats showed exponential increases through 2014, followed by a plateau or slight decline in recent years. An oscillating pattern may suggest density-dependent feedbacks which drive populations towards carrying capacity, or the biomass of individuals that the environment can support at any one time (Lorenzen \& Enberg 2002). Recent evidence of lionfish population declines on patch reefs in The Bahamas, another region with previously high (>10 fish $100 \mathrm{~m}^{-2}$ ) densities, may also be the result of density-dependent feedbacks on those populations (Benkwitt et al. 2017).

Density-dependent effects on demographic rates (e.g. growth, fecundity, mortality) are responsible for regulating population growth (Jenkins et al. 1999, Post et al. 1999) and may act strongly on invasive species over time as populations establish and grow rapidly towards carrying capacity (Bøhn et al. 2004, Gutowsky \& Fox 2012). At high densities, density dependence regulates growth of juveniles and adults via increased inter- and intra-specific competition and a scarcity of resources available to sustain individuals (Jenkins et al. 1999, Smith \& Smith 2001, Lorenzen \& Enberg 2002). Potential consequences of densitydependent growth include changes in populationlevel fecundity and mortality, which are both strongly related to body size (Lorenzen 1996, Lorenzen \& Enberg 2002).

Artificial reefs in the nGOM have significantly different reef fish communities compared to natural hard-bottom reefs, notably with much lower densities of small demersal fishes (e.g. damselfishes, blennies, gobies, and wrasses) (Dance et al. 2011, Patterson et al. 2014, Dahl et al. 2016) that have been shown to be the predominant prey among lionfish sampled at natural reefs throughout the nGOM (Dahl
\& Patterson 2014, Dahl et al. 2017). High lionfish densities observed on artificial reefs are more likely to drive local depletions in prey species, forcing lionfish to increase foraging distance from reefs or time spent hunting prey. Indeed, lionfish collected from nGOM artificial reefs in 2013 and 2014 were seen to supplement their diets with non-reef associated prey (Dahl \& Patterson 2014), thus indicating strong competition for local prey resources and conveying consequences of slower growth and lower body condition (Coulter et al. 2018, this study). We report here that body condition on natural reefs declined in later years of the invasion as lionfish biomass increased. Therefore, low condition observed on artificial reefs across the study may indicate density-dependent feedbacks acting on nGOM lionfish populations as early as 2013, as densities were consistently high during sampling years for age and growth analyses.

Lionfish condition and size-at-age were negatively related to density on nGOM artificial reefs, suggesting the overall effect of habitat on lionfish growth in the region was due to stark differences in density between artificial and natural reefs. Clearly, density is a strong predictor of mean TL, where each additional lionfish per $100 \mathrm{~m}^{2}$ resulted in fish being $0.46 \mathrm{~mm}$ TL shorter at age on nGOM artificial reefs when accounting for age class and sex. These trends translated into large differences in mean TL (approximately $30-70 \mathrm{~mm}$ ) between the lowest and highest density sites sampled. A reduction in the mean size of lionfish is a desirable management outcome given that body size is a major determinant of lionfish energetic demands and diet. Larger, mature individuals

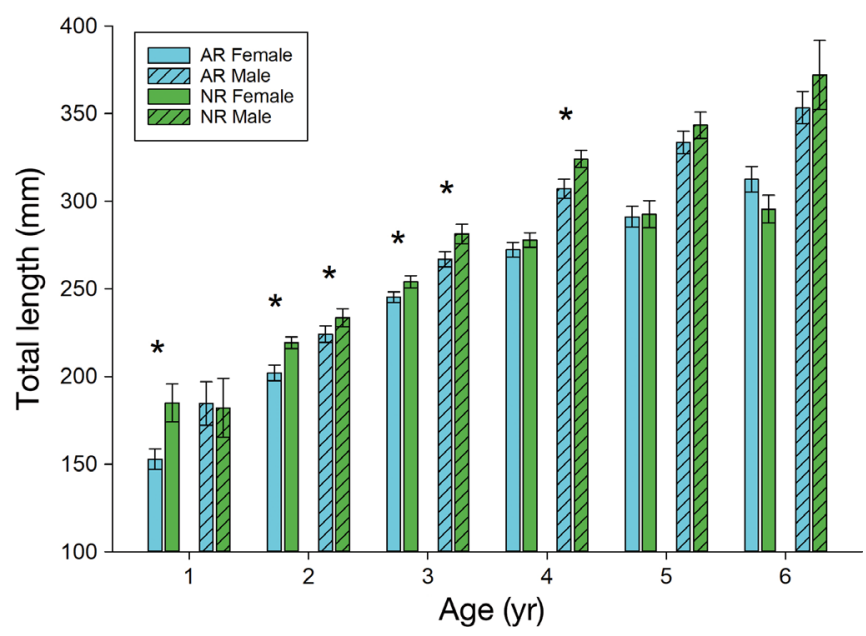

Fig. 8. Mean $( \pm 95 \% \mathrm{CI})$ size-at-age of lionfish by sex and habitat for ages $1-6$ yr. Asterisks: significant $(\alpha<0.05)$ effect of habitat within sex and year class (ANOVA; Table 2). AR: artificial reef; NR: natural reef 


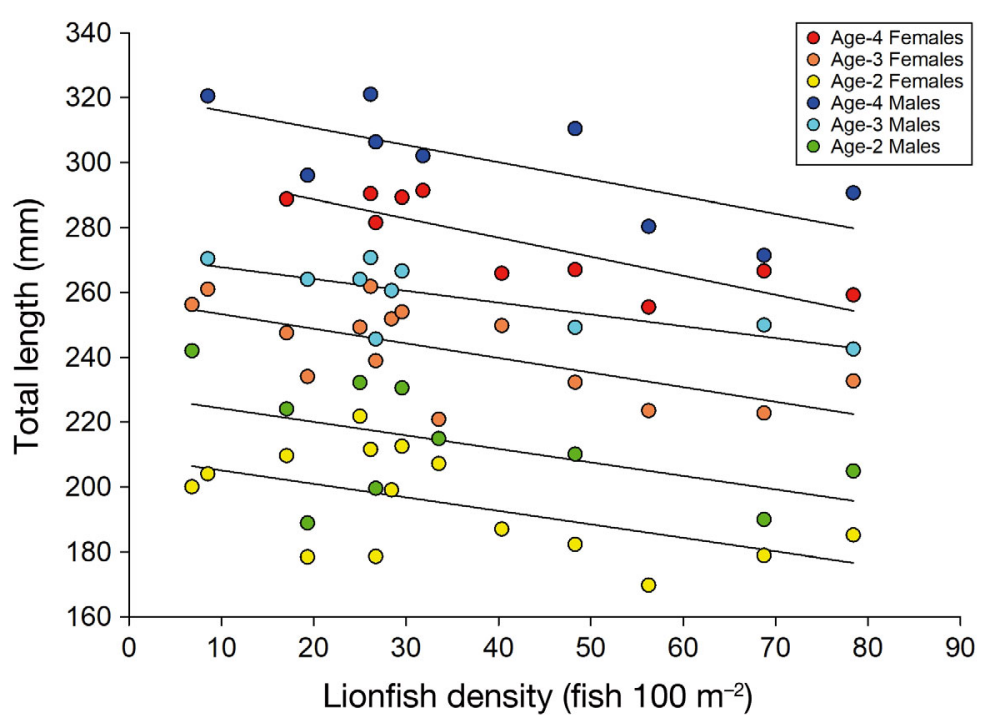

Fig. 9. Mean size-at-age versus lionfish density at sampled artificial reefs for male and female lionfish between ages 2-4 yr. Plotted lines: sex- and age-specific linear regressions. Each data point represents the mean of all individuals sampled at a given site

have higher energetic demands and consume prey at higher rates than smaller sized individuals (Cerino et al. 2013). Fish also represent a higher proportion of lionfish diet for larger individuals; therefore, a population of mostly smaller lionfish may reduce cumulative predation on vulnerable prey fishes (Morris \& Akins 2009, Dahl \& Patterson 2014).

An implicit assumption of relating size-at-age to lionfish density is that densities estimated at reefs were experienced over the lifetime of lionfish sampled there (i.e. high site fidelity and reef residency). Results of studies examining lionfish post-settlement movement indicate lionfish generally display high site fidelity (Akins et al. 2014, Bacheler et al. 2015), but emigration may increase under high density conditions (Tamburello \& Côté 2015). In the nGOM region, experimental removals performed in the same system revealed adult movement onto cleared reefs, where reefs were separated by $0.3-1 \mathrm{~km}$ and were distant $(>5 \mathrm{~km}$ ) from nearby natural habitat (Dahl et al. 2016). One aim of ongoing research in this respect is to explicitly test for potential density-dependent dispersal among reefs, using acoustic telemetry.

Additional evidence of density-dependent processes resulting from intra-specific competition includes density-dependent cannibalism of juveniles observed among nGOM lionfish (Dahl et al. 2018). Cannibalism was documented in lionfish sampled from both habitats between 2013 and 2014 which increased in frequency through time, mirroring increases in lion- fish density. Incidence of cannibalism is influenced by a variety of factors, namely prey availability and conspecific density, and benefits of the behavior include increased growth and survival, and decreased intra-specific competition (Pereira et al. 2017). In this system, juvenile lionfish appear to recruit to the same offshore reefs inhabited by adults, leading to increased rates of cannibalism via a lack of habitat separation and high encounter rates between different life stages (Claydon et al. 2012, Dahl et al. 2018). Cannibalism acts as another density-dependent feedback mechanism by which populations may persist through time, whereby lionfish may feed on conspecifics when preferred prey are depleted or unavailable (Polis 1981). While it remains unknown to what extent cannibalism may regulate invasive lionfish populations, smaller and younger fish were infrequently observed in later years of our study, which may indicate higher rates of cannibalism across time as prey demand increased with increasing regional lionfish biomass (Dahl et al. 2018).

Density-dependent processes may also be compensatory such that increases in population growth rate can occur when populations are at low densities (Rose et al. 2001). Management efforts that directly remove lionfish temporarily lower their density (Frazer et al. 2012, Dahl et al. 2016), but remaining

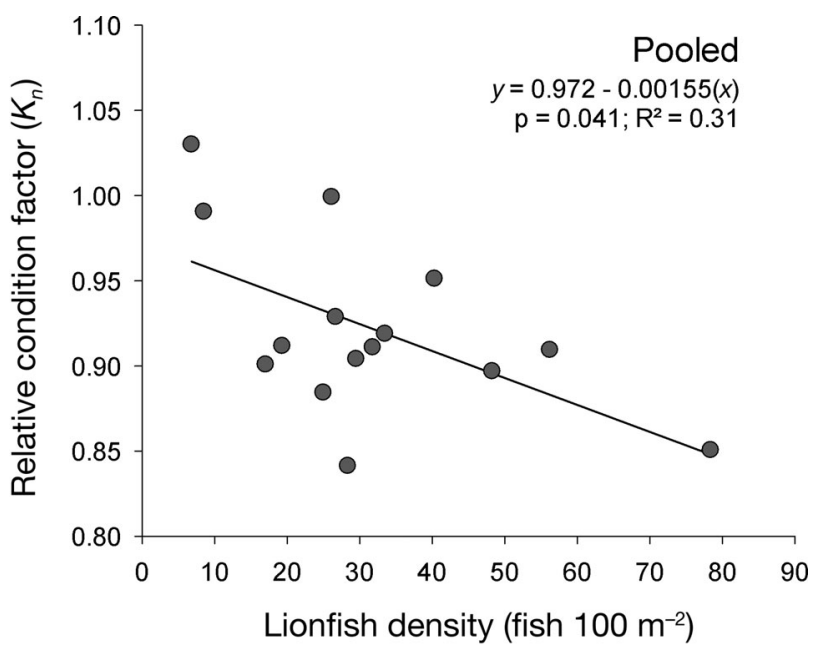

Fig. 10. Relative condition factor versus lionfish density at sampled artificial reefs. Plotted line: linear regression fit to the data. Each data point represents the mean of all individuals sampled at a given site 
individuals may be released from density-dependent mechanisms. Compensatory demographic rates such as increased growth, survival, or recruitment at lower lionfish density following culling events may unintentionally hinder management efforts that aim to reduce lionfish impacts. Among fish, longevity and high fecundity predict strong compensatory responses in population growth (Rose et al. 2001). It is predicted that lionfish may live upwards of $10 \mathrm{yr}$ in the wild (Potts et al. 2010), and fecundity is relatively high (Fogg et al. 2017). Therefore, future studies should be designed to monitor for compensatory changes in growth, survival, or recruitment of lionfish following targeted removals.

\subsection{Age and growth in the nGOM}

The nGOM lionfish sampled during this study were comprised of males and females aged 0.2-7.7 yr, with the majority of fish aged 1-4 yr old. Although lionfish were first reported on nGOM habitats in fall 2010, back-calculated birth dates from individual age estimates indicate fish may have started colonizing the region as early as 2008, but were at densities too low to be detected. Our overall (joint-sex) estimates of $L_{\infty}$ (381.3 mm) and $k\left(0.30 \mathrm{yr}^{-1}\right)$ are generally consistent with results from previous studies on lionfish in the western Atlantic (Potts et al. 2010, Barbour et al. 2011, Fogg 2017). Lionfish in North Carolina, where they have the oldest established populations (Potts et al. 2010), had the greatest length asymptote $\left(L_{\infty}=\right.$ $455 \mathrm{~mm})$, and lionfish were reported to grow fastest $\left(k=0.56 \mathrm{yr}^{-1}\right)$ immediately following initial colonization (2012-2014) in the GOM (Fogg 2017), compared to pooled data from the current study $\left(L_{\infty}=381 \mathrm{~mm}\right.$ and $k=0.30 \mathrm{yr}^{-1}$ ). Variation in growth estimates between this study and Fogg (2017) could be explained by a number of different factors including model fitting methods, sampling period, elapsed time since colonization, environmental factors (e.g. temperature regimes), sampling methods (e.g. divers, tournaments, traps, hook-and-line fishing), or regional differences in lionfish density or prey availability.

Von Bertalanffy growth models are useful for comparison among regions or studies given the range of studies in which lionfish VBGFs have been computed. However, VBGF parameters are known to be influenced by sample size, especially for data sets that lack smaller or larger fish (Gwinn et al. 2010, Wilson et al. 2015). Therefore, a more useful means to compare growth between sexes or habitats is to test for differences in size-at-age directly. For exam- ple, in the current study, lionfish on natural reefs were significantly larger at age than those from artificial reefs, but significance varied by sex and year class. Significant differences were identified between ages 1-3 yr for females, and between ages 2-4 yr for males. Given that females reach maximum reproductive output at larger body sizes (i.e. older ages), a greater amount of energy diverted from somatic growth into gamete production would likely explain similarities in size-at-age of older females between habitats (Fogg 2017). Smaller size-at-age seen in older males on artificial reefs may reflect higher prey demands required for larger body sizes to maintain the same rate of growth coupled with lower prey diversity and abundance on artificial reefs (Dahl et al. 2016). An alternative explanation is that older males on high density artificial reefs expend more energy on behaviors related to mating, such as agonistic behaviors of competing males (Fishelson 1975, Fogg \& Faletti 2018).

Finally, sex-specific size-at-age for nGOM lionfish indicates sexually dimorphic growth across the study, where mean size-at-age of males was significantly larger than females. This pattern was apparent across all ages on both natural and artificial reefs, with the exception of age-1 fish on natural reefs. Overall, female lionfish in the nGOM achieved an average maximum length that was only $84 \%$ of that of males but reached their asymptotic maximum length $1.3 \times$ faster (i.e. higher $k$ ). Lionfish growth was rapid for both sexes across the study with male and female fish reaching $50 \%$ of their $L_{\infty}$, averaged across habitats, within 1.9 and $1.5 \mathrm{yr}$, respectively. While growth slowed significantly after age 4 in females, steady growth continued in males through older age classes. Sexually dimorphic growth has been reported for lionfish in the invaded range (Edwards et al. 2014, Fogg 2017), as well as for a number of other scorpaenids (Kelly et al. 1999, Bilgin \& Çelik 2009, La Mesa et al. 2010), where it is recognized that females grow slower in older age classes due to the higher energy expenditure of egg production (Cerino et al. 2013).

\section{CONCLUSIONS AND IMPLICATIONS}

The comprehensive lionfish size-at-age data set presented herein and collected over a $5 \mathrm{yr}$ period of invasion in the nGOM provides evidence of densitydependent feedbacks on lionfish condition and growth, which may be due to either intra- or interspecific competition. Lionfish populations regulated 
more by intra-specific competition for limited resources describe a worst-case invasion scenario of invaders released from natural sources of population control and an invaded community exhibiting little biotic resistance to invasion (Albins \& Hixon 2013). Fortunately, a rise in biotic resistance to previously unchecked lionfish populations in the western Atlantic may be occurring. Inter-specific competition (Chagaris et al. 2017) and emerging pathogens (Harris et al. 2018) may negatively impact lionfish populations in the region and provide additional population control mechanisms beyond intra-specific competition. Taken together with density-dependent effects on growth reported here, trends in population density signal that lionfish may be reaching carrying capacity in the nGOM (Simberloff \& Gibbons 2004). While we may not have captured the full extent of density-dependent effects possible as the invasion time series continues in the nGOM, temporal trends in age and growth of lionfish observed in this study illustrate the importance of invasion stage in influencing population dynamics of invasive species (Bøhn et al. 2004). In the years immediately following invasion, lionfish exhibited traits of rapid population growth, but in later years these traits shifted to reflect density-dependent limitations on lionfish, which highlights the role of density in structuring invasive lionfish populations. Future studies should examine other potential density-dependent demographic rates (e.g. movement, fecundity, mortality) in invasive lionfish populations. Ultimately, sex- and habitat-specific growth coefficients from this study may inform previously parameterized models (e.g. Barbour et al. 2011, Chagaris et al. 2017) to assess the level of removal effort required to induce recruitment overfishing and to incorporate potential compensatory growth that may hamper future removal efforts.

Acknowledgements. We thank Dalton Kennedy, Clint Retherford, Scott Bartel, Josh and Joe Livingston, Andy Ross, Alex Fogg, Holden Harris, Meaghan Faletti, Bob and Carol Cox, Bryan and Anna Clark, and Grayson Shepherd for help in collecting and spearing lionfish. We thank Brian Klimek, Steve Garner, Miaya Glabach, Joe Tarnecki, Jordan Bajema, Beverly Barnett, Erin Bohaboy, Justin Lewis, Holden Harris, Joe Kuehl, Gracie Barnes, and Sarah Friedl for help in the field collecting lionfish and in the laboratory processing samples. This research was made possible in part by a grant from The Gulf of Mexico Research Initiative/C-IMAGE III. Data (https://doi.org/10.7266/n7-krwm-b876) are publicly available through the Gulf of Mexico Research Initiative Information and Data Cooperative (GRIIDC) at https://data. gulfresearchinitiative.org. This research was also made possible by funding from the Florida Fish and Wildlife Conservation Commission and Mississippi Alabama Sea Grant (USM-GR03924-R-HCE-04-PD).

\section{LITERATURE CITED}

Akins JL, Morris JA Jr, Green SJ (2014) In situ tagging technique for fishes provides insight into growth and movement of invasive lionfish. Ecol Evol 4:3768-3777

Albins MA, Hixon MA (2013) Worst case scenario: potential long-term effects of invasive predatory lionfish (Pterois volitans) on Atlantic and Caribbean coral-reef communities. Environ Biol Fishes 96:1151-1157

* Bacheler NM, Whitfield PE, Muñoz RC, Harrison BB, Harms CA, Buckel CA (2015) Movement of invasive adult lionfish Pterois volitans using telemetry: importance of controls to estimate and explain variable detection probabilities. Mar Ecol Prog Ser 527:205-220

* Barbour AB, Montgomery ML, Adamson AA, Díaz-Ferguson E, Silliman BR (2010) Mangrove use by the invasive lionfish Pterois volitans. Mar Ecol Prog Ser 401:291-294

* Barbour AB, Allen MS, Frazer TK, Sherman KD (2011) Evaluating the potential efficacy of invasive lionfish (Pterois volitans) removals. PLOS ONE 6:e19666

Beamish RJ, Fournier DA (1981) A method for comparing the precision of a set of age determinations. Can J Fish Aquat Sci 38:982-983

Beckman DW, Stanley AL, Render JH, Wilson CA (1991) Age and growth-rate estimation of sheepshead Archosargus probatocephalus in Louisiana waters using otoliths. Fish Bull 89:1-8

Benkwitt CE (2013) Density-dependent growth in invasive lionfish (Pterois volitans). PLOS ONE 8:e66995

Benkwitt CE, Albins MA, Buch KL, Ingeman KE and others (2017) Is the lionfish invasion waning? Evidence from The Bahamas. Coral Reefs 36:1255-1261

* Bilgin S, Çelik E (2009) Age, growth and reproduction of the black scorpionfish, Scorpaena porcus (Pisces, Scorpaenidae), on the Black Sea coast of Turkey. J Appl Ichthyology 25:55-60

* Bøhn T, Sandlund OT, Amundsen PA, Primicerio R (2004) Rapidly changing life history during invasion. Oikos 106: 138-150

Campana SE (2001) Accuracy, precision and quality control in age determination, including a review of the use and abuse of age validation methods. J Fish Biol 59:197-242

* Cerino D, Overton AS, Rice JA, Morris JA Jr (2013) Bioenergetics and trophic impacts of the invasive Indo-Pacific lionfish. Trans Am Fish Soc 142:1522-1534

* Chagaris D, Binion-Rock S, Bogdanoff A, Dahl K and others (2017) An ecosystem-based approach to evaluating impacts and management of invasive lionfish. Fisheries (Bethesda, Md) 42:421-431

* Claydon J, Calosso M, Traiger S (2012) Progression of invasive lionfish in seagrass, mangrove and reef habitats. Mar Ecol Prog Ser 448:119-129

* Côté IM, Maljkovi A (2010) Predation rates of Indo-Pacific lionfish on Bahamian coral reefs. Mar Ecol Prog Ser 404: 219-225

* Côté IM, Green SJ, Hixon MA (2013) Predatory fish invaders: insights from Indo-Pacific lionfish in the western Atlantic and Caribbean. Biol Conserv 164:50-61

Coulter DP, MacNamara R, Glover DC, Garvey JE (2018) Possible unintended effects of management at an invasion front: reduced prevalence corresponds with high condition of invasive bigheaded carps. Biol Conserv 221: 118-126

Crooks JA, Soule ME (1999) Lag times in population explosions of invasive species: causes and implications. In: 
Sandlund OT, Schei PJ, Viken A (eds) Invasive species and biodiversity management. Kluwer Academic Publishers, London, p 103-125

* Dahl KA, Patterson WF III (2014) Habitat-specific density and diet of rapidly expanding invasive red lionfish, Pterois volitans, populations in the northern Gulf of Mexico. PLOS ONE 9:e105852

Dahl KA, Patterson WF III, Snyder RA (2016) Experimental assessment of lionfish removals to mitigate reef fish community shifts on northern Gulf of Mexico artificial reefs. Mar Ecol Prog Ser 558:207-221

Nahl KA, Patterson WF III, Robertson A, Ortmann AC (2017) DNA barcoding significantly improves resolution of invasive lionfish diet in the northern Gulf of Mexico. Biol Invasions 19:1917-1933

Dahl KA, Portnoy DS, Hogan JD, Johnson JE, Gold JR, Patterson WF III (2018) Genotyping confirms significant cannibalism in northern Gulf of Mexico invasive red lionfish, Pterois volitans. Biol Invasions 20:3513-3526

Dance MA, Patterson WF III, Addis DT (2011) Fish community and trophic structure at artificial reef sites in the northeastern Gulf of Mexico. Bull Mar Sci 87:301-324

* Darling ES, Green SJ, O'Leary JK, Côté IM (2011) IndoPacific lionfish are larger and more abundant on invaded reefs: a comparison of Kenyan and Bahamian lionfish populations. Biol Invasions 13:2045-2051

Edwards MA, Frazer TK, Jacoby CA (2014) Age and growth of invasive lionfish (Pterois spp.) in the Caribbean Sea, with implications for management. Bull Mar Sci 90: 953-966

Fishelson L (1975) Ethology and reproduction of pteroid fishes found in the Gulf of Aqaba (Red Sea), especially Dendrochirus brachypterus (Cuvier), (Pteroidae, Teleostei). Pubbl Stn Zool Napoli 39:635-656

Fogg AQ (2017) Life history of the non-native invasive red lionfish (Pterois volitans) in the northern Gulf of Mexico. MSc thesis, University of Southern Mississippi, Ocean Springs, MS

Fogg AQ, Faletti ME (2018) Invasive lionfish (Pterois sp.) agonistic behavior observations. Bull Mar Sci 94:1-2

Fogg AQ, Hoffmayer ER, Driggers WB III, Campbell MD, Pellegrin GJ, Stein W (2013) Distribution and length frequency of invasive lionfish (Pterois sp.) in the northern Gulf of Mexico. Gulf Caribb Res 25:111-115

Fogg AQ, Brown-Peterson NJ, Peterson MS (2017) Reproductive life history characteristics of invasive red lionfish (Pterois volitans) in the northern Gulf of Mexico. Bull Mar Sci 93:791-813

Frazer TK, Jacoby CA, Edwards MA, Barry SC, Manfrino CM (2012) Coping with the lionfish invasion: Can targeted removals yield beneficial effects? Rev Fish Sci 20:185-191

Green SJ, Akins JL, Maljkovi A, Côté IM (2012) Invasive lionfish drive Atlantic coral reef fish declines. PLOS ONE 7:e32596

* Gutowsky LFG, Fox MG (2012) Intra-population variability of life-history traits and growth during range expansion of the invasive round goby, Neogobius melanostomus. Fish Manag Ecol 19:78-88

Gwinn DC, Allen MS, Rogers MW (2010) Evaluation of procedures to reduce bias in fish growth parameter estimates resulting from size-selective sampling. Fish Res 105:75-79

Hackerott S, Valdivia A, Green SJ, Côté IM and others (2013) Native predators do not influence invasion success of Pacific lionfish on Caribbean reefs. PLOS ONE 8:e68259
Harris HE, Fogg AQ, Yanong RPE, Frasca $\mathrm{S}$, Cody $\mathrm{T}$, Waltzek TB, Patterson WF III (2018) First report of an emerging ulcerative skin disease in invasive lionfish. Publication No. FA209. University of Florida Institute of Food and Agricultural Sciences Extension, Gainesville. http://edis.ifas.ufl.edu/fa209 (accessed 10 Sep 2018)

* Hoenig JM, Morgan MJ, Brown CA (1995) Analysing differences between two age determination methods by tests of symmetry. Can J Fish Aquat Sci 52:364-368

* Jenkins TM, Diehl S, Kratz KW, Cooper SD (1999) Effects of population density on individual growth of brown trout in streams. Ecology 80:941-956

* Johnson EG, Swenarton MK (2016) Age, growth and population structure of invasive lionfish (Pterois volitans/ miles) in northeast Florida using a length-based, agestructured population model. PeerJ 4:e2730

K Kelly CJ, Connolly PL, Bracken JJ (1999) Age estimation, growth, maturity, and distribution of the bluemouth rockfish Helicolenus d. dactylopterus (Delaroche 1809) from the Rockall Trough. ICES J Mar Sci 56:61-74

Kimura DK, Lyons JJ (1991) Between-reader bias and variability in the age-determination process. Fish Bull 89: 53-60

Kolar CS, Lodge DM (2001) Progress in invasion biology: predicting invaders. Trends Ecol Evol 16:199-204

Kulbicki M, Beets J, Chabanet P, Cure K and others (2012) Distributions of Indo-Pacific lionfishes Pterois spp. in their native ranges: implications for the Atlantic invasion. Mar Ecol Prog Ser 446:189-205

* La Mesa M, Scarcella G, Grati F, Fabi G (2010) Age and growth of the black scorpionfish, Scorpaena porcus (Pisces: Scorpaenidae) from artificial structures and natural reefs in the Adriatic Sea. Sci Mar 74:677-685

* Le Cren ED (1951) The length-weight relationship and seasonal cycle in gonad weight and condition in the perch (Perca fluviatilis). J Anim Ecol 20:201-219

Lesser MP, Slattery M (2011) Phase shift to algal dominated communities at mesophotic depths associated with lionfish (Pterois volitans) invasion on a Bahamian coral reef. Biol Invasions 13:1855-1868

Lockwood JL, Hoopes MF, Marchetti MP (2007) Invasion ecology. Wiley-Blackwell, West Sussex

* Lorenzen K (1996) The relationship between body weight and natural mortality in juvenile and adult fish: a comparison of natural ecosystems and aquaculture. J Fish Biol 49:627-647

* Lorenzen K, Enberg K (2002) Density-dependent growth as a key mechanism in the regulation of fish populations: evidence from among-population comparisons. Proc R Soc B 269:49-54

Morris JA Jr, Akins JL (2009) Feeding ecology of invasive lionfish (Pterois volitans) in the Bahamian archipelago. Environ Biol Fishes 86:389-398

Morris JA Jr, Akins J, Barse A (2009) Biology and ecology of the invasive lionfishes, Pterois miles and Pterois volitans. Proc Gulf Caribb Fish Inst 61:1-6

KMorris JA Jr, Shertzer KW, Rice JA (2011) A stage-based matrix population model of invasive lionfish with implications for control. Biol Invasions 13:7-12

*Muñoz RC, Currin CA, Whitfield PE (2011) Diet of invasive lionfish on hard bottom reefs of the Southeast USA: insights from stomach contents and stable isotopes. Mar Ecol Prog Ser 432:181-193

Nouttall M (2014) Lionfish (Pterois volitans [Linnaeus, 1758] and $P$. miles [Bennett, 1828]) records within mesophotic 
depth ranges on natural banks in the northwestern Gulf of Mexico. BioInvasions Rec 3:111-115

Patterson WF III, Dance MA, Addis DT (2009) Development of a remotely operated vehicle based methodology to estimate fish community structure at artificial reef sites in the northern Gulf of Mexico. Proc Gulf Caribb Fish Inst 61:263-270

Patterson WF III, Tarnecki JH, Addis DT, Barbieri LR (2014) Reef fish community structure at natural versus artificial reefs in the northern Gulf of Mexico. Proc Gulf Caribb Fish Inst 66:4-9

Pereira LS, Agostinho AA, Winemiller KO (2017) Revisiting cannibalism in fishes. Rev Fish Biol Fish 27:499-513

Polis GA (1981) The evolution and dynamics of intraspecific predation. Annu Rev Ecol Syst 12:225-251

Post JR, Parkinson EA, Johnston NT (1999) Density-dependent processes in structured fish populations: interaction strengths in whole-lake experiments. Ecol Monogr 69: 155-175

Potts JC, Berrane D, Morris JA Jr (2010) Age and growth of lionfish from the western North Atlantic. Proc Gulf Caribb Fish Inst 63:314

Core Team (2016) R: a language and environment for statistical computing. R Foundation for Statistical Computing, Vienna

Rose KA, Cowan JH, Winemiller KO, Myers RA, Hilborn R (2001) Compensatory density dependence in fish populations: importance, controversy, understanding and prognosis. Fish Fish 2:293-327

Sakai AK, Allendorf FW, Holt JS, Lodge DM and others (2001) The population biology of invasive species. Annu Rev Ecol Syst 32:305-332

Schofield PJ (2010) Update on geographic spread of invasive lionfishes (Pterois volitans [Linnaeus, 1758] and P. miles [Bennett, 1828]) in the western North Atlantic Ocean,

Editorial responsibility: Stylianos Somarakis, Heraklion, Greece
Caribbean Sea and Gulf of Mexico. Aquat Invasions 5: S117-S122

Schofield PJ, Langston JN, Morris JA Jr, Fuller P (2014) Pterois volitans/miles fact sheet. USGS Nonindigenous Aquatic Species Database. https://nas.er.usgs.gov/queries/ FactSheet.aspx? speciesID $=963$

Simberloff D, Gibbons L (2004) Now you see them, now you don't! - Population crashes of established introduced species. Biol Invasions 6:161-172

Smith RL, Smith TM (2001) Ecology and field biology, $6^{\text {th }}$ edn. Benjamin Cummings, San Francisco, CA

* Soupir CA, Blackwell BB, Brown ML (1997) Relative precision among calcified structures for white bass age and growth assessment. J Freshwat Ecol 12:531-538

* Tamburello N, Côté IM (2015) Movement ecology of IndoPacific lionfish on Caribbean coral reefs and its implications for invasion dynamics. Biol Invasions 17: 1639-1653

Thompson MJ, Schroeder WW, Phillips NW, Graham BD (1999) Ecology of live bottom habitats of the northeastern Gulf of Mexico: a community profile. Contractor report USGS/BRD/CR-1999-0001. US Dept of the Interior, US Geological Survey, Biological Resources Division, and Minerals Management Service, Gulf of Mexico OCS Region, New Orleans, LA

Tuttle LJ, Sikkel PC, Cure K, Hixon MA (2017) Parasitemediated enemy release and low biotic resistance may facilitate invasion of Atlantic coral reefs by Pacific red lionfish (Pterois volitans). Biol Invasions 19:563-575

von Bertalanffy L (1938) A quantitative theory of organic growth. Hum Biol 10:181-213

Wilson KL, Matthias BG, Barbour AB, Ahrens RNM, Tuten T, Allen MS (2015) Combining samples from multiple gears helps to avoid fishy growth curves. N Am J Fish Manage 35:1121-1131

Submitted: January 18, 2019; Accepted: June 9, 2019 Proofs received from author(s): July 20, 2019 